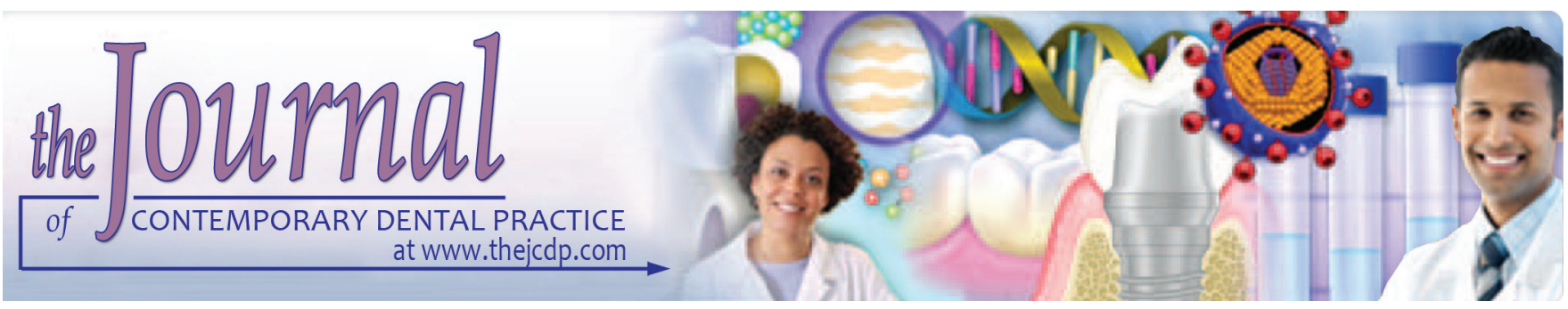

\title{
Status of Endodontic Treatment and the Correlations to the Quality of Root Canal Filling and Coronal Restoration
}

\author{
${ }^{1}$ Fabio M Pedro, ${ }^{2}$ ATC Marques, ${ }^{3}$ Thiago M Pereira, ${ }^{4}$ Matheus C Bandeca, ${ }^{5}$ SNL Lima \\ ${ }^{6}$ Milton C Kuga, ${ }^{7}$ Mateus R Tonetto, ${ }^{8}$ Alex Semenoff-Segundo, ${ }^{9}$ Alvaro H Borges
}

\begin{abstract}
Introduction: This cross-sectional study evaluated the prevalence and quality of root canal treatment in 1,977 digital radiological files.
\end{abstract}

Materials and methods: Data were statistically analyzed using descriptive analysis, and the chi-square test was performed with a $5 \%$ significance level.

Results: The mean age of the study population was 34.9 years. The endodontic treatment frequency was $6.14 \%$, significantly higher in premolars. Adequate endodontic treatment was observed in $39.7 \%$ of analyzed cases. Molars were significantly more frequent with regard to inadequate filling quality. In $47.6 \%$ of cases, the filling's apical limit was classified as adequate, and there was a higher incidence of molars that were inadequate. Restorations were classified as adequate in $79.0 \%$ of cases, and molars were responsible for the highest frequency of inadequate restorations. The frequency of teeth with endodontic treatment that showed no periapical changes was $47.7 \%$. There was no significant difference in the presence of periapical change according to gender. An increased presence of periapical change was observed with increasing age. The periapical lesions were observed in $45 \%$ of cases and related to inadequate filling quality. The apical limit was considered inadequate and related to periapical changes in $42 \%$ of cases. Periapical changes were present in $52 \%$ of cases, regardless of the quality of the filling and apical limit. Such changes were present in $42 \%$ of cases with adequate coronal restoration.

\footnotetext{
1-3,7-9 Department of Post-Graduate Program in Integrated Dental Science, Dental School, University of Cuiabá, Cuiabá, Brazil

${ }^{4,5}$ Department of Post-Graduate Program in Dentistry, CEUMA University, São Luis, Brazil

${ }^{6}$ Department of Restorative Dentistry, School of Dentistry Universidade Estadual Paulista, Araçatuba, Brazil

Corresponding Author: Alvaro $\mathrm{H}$ Borges, Department of Post-Graduate Program in Integrated Dental Science Dental School, University of Cuiabá, Cuiabá, Brazil, Phone: +556533631271, e-mail: alvarohborges@gmail.com
}

Conclusion: It can be concluded that apical periodontitis (AP) is associated with the quality of endodontic treatment. The coronal restoration affects significantly the success rate of endodontic treatment.

Clinical significance: The quality of the root filling and coronal restoration is closely related to periapical health.

Keywords: Endodontics, Panoramic, Radiography, Root canal preparation.

How to cite this article: Pedro FM, Marques ATC, Pereira TM, Bandeca MC, Lima SNL, Kuga MC, Tonetto MR, SemenoffSegundo A, Borges AH. Status of Endodontic Treatment and the Correlations to the Quality of Root Canal Filling and Coronal Restoration. J Contemp Dent Pract 2016;17(10):830-836.

Source of support: Nil

Conflict of interest: None

\section{INTRODUCTION}

Endodontic treatment is defined as a combination of mechanical instrumentation and chemical debridement, followed by filling with biocompatible material, to maintain or restore the health of the periapical tissue. ${ }^{1}$ Successful treatment depends on the knowledge of etiology, pathophysiology, and clinical manifestations. ${ }^{2,3}$ Many factors can influence prognosis, such as inadequate antisepsis, poor coronal access, inadequate instrumentation, nonobturated root canals, deficient restorations, preoperative status of the pulp tissue, microbiological culture before filling, apical limit, and presence of previous periapical lesions. ${ }^{4,5}$ Anatomical variability can also interfere on the prognosis. ${ }^{6,7}$

Technological advances in methods, instruments, and materials have provided better results; however, the discrepancy in success rates may reflect a difference in the quality of the performed endodontic treatment. ${ }^{8}$

Success rates are based on the absence of clinical and radiographic signs/symptoms of inflammation and 
infection. ${ }^{4}$ Epidemiological studies have documented the quality of endodontic treatment in several countries involving different populations by evaluating radiographic parameters of apical limits and filling homogeneity. ${ }^{8-10}$ The absence of a coronal seal due to missing or improper restoration allows bacteria and bacterial factors in the oral cavity to penetrate the filling material and eventually reach the apical foramen, influencing treatment success. ${ }^{11}$

Although the periradicular tissue produces a variety of responses to infectious process, liable to restrict the propagation of infectious elements, the apical periodontitis (AP) should not be considered an exclusively local phenomenon. ${ }^{12}$ Therefore, the spread of infection to surrounding tissue compartments is possible and can be related to serious implications. ${ }^{13,14}$ Endodontic health planning for a population allows an understanding of the disease's relationships and involves a preventive approach and analysis of their distribution, prevalence, severity, and risk factors. ${ }^{15}$ Epidemiological studies in different societies contribute through the observation of factors associated with the health/disease process, providing important information for the development of preventive or therapeutic strategies and for understanding their results. ${ }^{16}$

The present study aimed to evaluate the prevalence and quality of root canal treatment, the prevalence of periapical radiolucency, and the quality of coronal restoration using routine imaging exams.

\section{MATERIALS AND METHODS}

This cross-sectional study analyzed 1,977 digital radiological files belonging to a specialized radiology clinic.
Of these, 1,398 panoramic radiographs taken with KODAK 9000C 3D equipment (KODAK Dental System group, Carestream Dental LLC, Atlanta, GA, USA) were selected as the study sample. Radiographic evaluation was performed after approval of the research project by the Research Ethics Committee under Protocol No. 2012-060. The inclusion criteria were panoramic radiographs showing high technical standard and quality with regard to density and contrast. Radiographs of completely edentulous patients and patients with the presence of orthodontic appliances and/or the presence of implants that overlapped the roots of the endodontically treated teeth, precluding evaluation, were discarded. Files without the presence of panoramic radiographs were also discarded, totaling 579 .

The study included patients, males and females, aged 15 to 65 years. Two calibrated endodontics specialist evaluators with over 10 years of experience analyzed the radiographs. Calibration was performed during the pilot study by determining the periapical index (PAI) and endodontic treatment quality. Values of 0.89 for the AP index and 0.87 for endodontic treatment quality were obtained. Evaluation was performed on a 20" Samsung liquid crystal display screen using resources from Trophy DICOM 6.2 software, Kodak Imaging System, Carestream Health (KODAK Dental System group, Carestream Dental LLC, Atlanta, GA, USA). These features included standard image (Fig. 1A), inverted image (Fig. 1B), magnification (Fig. 1C), densitometric analysis (Fig. 1D), rules for length and maximum magnification measurements, which were provided by the program itself in DICOM format.

The results were compiled on a spreadsheet created especially for this purpose. Each dental element was
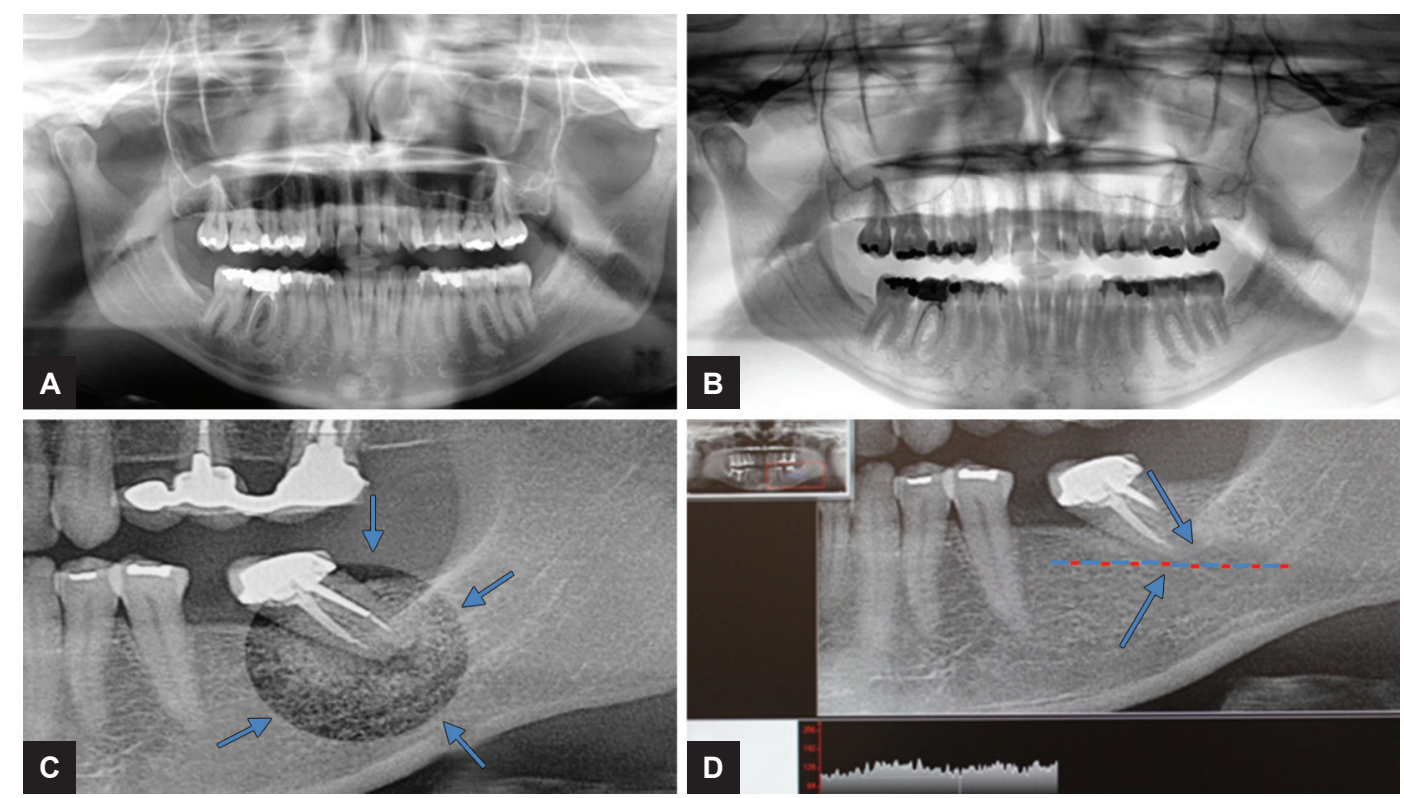

Figs 1A to D: (A) Standard image in panoramic radiograph; (B) inverted image; (C) magnification; and (D) densitometric analysis 
individually evaluated, and the following categories were determined: (1) Missing tooth; (2) tooth without endodontic treatment; and (3) tooth treated endodontically. For analysis of endodontic treatments, the following qualities were observed: Fillings, coronal restoration, and presence of periapical lesions. The criteria used for radiographic analysis of filling and restoration quality were as follows ${ }^{10}$ : Filling quality [(1) adequate - all canals were obturated, without voids, and the top of the root canal filling was 0 to $2 \mathrm{~mm}$ short of the radiographic apex; (2) inadequate - the top of the root canal filling was more than $2 \mathrm{~mm}$ short of the radiographic apex or was grossly overobturated with the presence of voids and inadequate density]. Coronal restoration was evaluated as follows: (1) Adequate - intact with good margin of adaptation and without recurrent signs of decay; (2) inadequate open margins, recurrent decay, or absence of restoration. Periapical status was evaluated using the PAI cited by Orstavik et $a 1^{17}$ : (1) Normal periapical structures, (2) small changes in bone structure, (3) changes in bone structure with small mineral loss, (4) clearly visible periodontitis with radiolucent area, and (5) advanced form of periodontitis with exacerbated appearance. A PAI score of 1 was defined as a healthy periapical region, i.e., normal periodontal ligament thickness and bone density showing normal appearance. All other PAI scores (2, 3, 4, and 5) were evaluated as AP. Multirooted teeth were graded according to the root exhibiting the most severe condition.

Data were statistically analyzed using descriptive analyses (simple and relative frequencies), and the chi-square test was performed to check the data significance level. Analyzed factors were prevalence of endodontic treatment, quality of endodontic treatment (filling quality and apical limit), prevalence of $\mathrm{AP}$, and coronal restoration quality. These factors were related to dental group, gender, and age.

\section{RESULTS}

The study included 1,398 individuals, aged between 15 and 65 years, with a mean of 34.9 years. A total of 37,928 teeth were analyzed; of these, 2,329 (6.14\%) had been subjected to endodontic treatment. Table 1 shows the analysis of endodontic treatment frequency regarding dental groups. Upon analyzing the dental groups, the molars had the highest frequency of inadequate restorations $(25.6 \%, \mathrm{p}<0.05)$, and the incisors had the lowest frequency of inadequate restorations $(16.3 \%, \mathrm{p}<0.05)$. A total of $47.7 \%$ of teeth with endodontic treatment showed no periapical changes. The molar group had the highest frequency of $\mathrm{AP}(67.3 \%, \mathrm{p}<0.05)$, and $5 \%$ of these teeth were at levels 3 and 4 of the PAI scoring system. The incisor group had the lowest frequency of teeth with periapical changes $(36.1 \%, \mathrm{p}<0.05)$. Comparing upper
Table 1: Analysis of endodontic status regarding dental groups (\%)

\begin{tabular}{lllll}
\hline Dental Group/ & & & & \\
Endodontic Status & Incisors & Canines & Premolars & Molars \\
\hline Not treated & 94.99 & 96.36 & 91.76 & 93.49 \\
Treated & $5.01^{\mathrm{b} *}$ & $3.64^{\mathrm{C}}$ & $8.24^{\mathrm{a}}$ & $6.51^{\mathrm{b}}$ \\
\hline Total & 100.0 & 100.0 & 100.0 & 100.0 \\
\hline
\end{tabular}

*Different letters represent statistically significant differences $(p<0.05)$

and lower teeth, a higher percentage of lower teeth lacked endodontic treatment $(p<0.05)$. Only the molar group had a higher percentage of upper teeth without endodontic treatment $(p<0.05)$. The $p$ value demonstrates a significant difference between upper and lower teeth. The lower incisors showed the lowest percentage of endodontic treatment (1.1\%). Statistically significant differences $(p<0.05)$ between upper and lower teeth were observed in all groups regarding the presence of periapical changes. These differences were especially apparent in the premolars and molars, where the upper teeth had a greater presence of periapical change, especially the upper $(74.3 \%)$ and lower molars $(61.7 \%)$. There was no statistically significant difference $(p<0.05)$ in the presence or absence of periapical changes according to gender for the canine and premolar groups. Only the molar groups showed a statistically significant difference $(p<0.05)$. The incisors were within the analysis limit for significance. When all dental groups were considered, there was no significant difference between genders $(p<0.05)$. Regarding age group, there was an increased presence of periapical changes with increasing age.

Table 2 shows the analysis of filling quality regarding dental groups. Of the analyzed teeth, $39.7 \%$ had adequate endodontic treatment. There was also a greater percentage of inadequate obturation with increasing age. That is, the percentage of teeth with obturations that were considered adequate was higher in younger patients, with the exception of the molar group, which exhibited no differences in terms of age for either the presence of periapical changes or obturation quality. Correlation analysis between the presence of periapical changes and obturation quality revealed that when obturation quality was classified as adequate, periapical changes were present in $7 \%$ of cases. However, when obturation quality was considered inadequate, periapical changes

Table 2: Analysis of filling quality regarding dental groups (\%)

\begin{tabular}{llllll}
\hline Dental group/ & & & & & \\
Filling quality & Incisors & Canines & Premolars & Molars & Total \\
\hline Adequate & 55.6 & 40.4 & 41.6 & 26.8 & 39.7 \\
Inadequate & $44.4^{\text {c**}}$ & $59.6^{\mathrm{b}}$ & $58.4^{\mathrm{b}}$ & $73.2^{\mathrm{a}}$ & 60.3 \\
\hline
\end{tabular}

${ }^{*}$ Different letters represent statistically significant differences $(p<0.05)$ 
Table 3: Analysis of apical limit regarding dental groups (\%)

\begin{tabular}{llllll}
\hline Dental group/ & & & & & \\
Apical limit & Incisors & Canines & Premolars & Molars & Total \\
\hline Adequate & 65.2 & 48.5 & 47.8 & 35.2 & 47.6 \\
Inadequate & $34.8^{\mathrm{c} *}$ & $51.5^{\mathrm{b}}$ & $52.2^{\mathrm{b}}$ & $64.8^{\mathrm{a}}$ & 52.4 \\
\hline
\end{tabular}

*Different letters represent statistically significant differences $(p<0.05)$

were present in $45 \%$ of endodontically treated teeth, a difference that was statistically significant $(\mathrm{p}<0.05)$. When the apical limit was considered adequate, periapical changes were present in $10 \%$ of cases. When the apical limit was considered inadequate, periapical changes were present in $42 \%$ of cases of endodontic treatment, a difference that was also statistically significant $(\mathrm{p}<0.05)$. In total, periapical changes were present in $52 \%$ of cases, regardless of obturation quality and the apical limit of the obturation.

Table 3 shows the analysis of apical limit regarding dental groups. In relation to the apical limit of obturation, 1,108 teeth were classified as adequate. In $79.0 \%$ of cases, restorations in endodontically treated teeth were classified as adequate, and inadequate in $21.0 \%$ of cases. Periapical changes were absent in $42 \%$ of cases where coronal restoration was adequate and were present in $37 \%$ of cases where coronal restoration was considered adequate. In $15 \%$ of cases, the coronal restoration was considered inadequate and associated with periapical changes. However, periapical lesions were absent in only $6 \%$ of all cases of inadequate coronal restorations, a difference that was statistically significant $(\mathrm{p}<0.05)$.

\section{DISCUSSION}

Epidemiological studies are essential in planning health measures and evaluation of measures taken. ${ }^{16}$ Knowledge of epidemiological factors associated with endodontic treatment is essential for the adoption of preventive measures and the establishment of more effective treatment protocols. ${ }^{15}$ In this context, action planning involves the need for knowledge about the distribution, prevalence, and severity of a given disease. ${ }^{16}$ Epidemiological studies have documented the quality of endodontic treatment in several countries involving different populations by evaluating radiographic parameters of apical limit and filling homogeneity. ${ }^{4,8-10}$

Digital panoramic radiographs enable analysis in a single field, allowing all teeth to be seen, reducing the patient's radiation dose by up to 10 -fold compared with a full periapical radiographic examination; in addition, the image capture is simple and fast and works on patients who are unable to open their mouths. ${ }^{18}$ At the same time, modern diagnostic imaging resources, such as cone beam computed tomography ( $\mathrm{CBCT}$ ), have demonstrated the projection of three-dimensional (3D) images, making this form of imaging particularly suitable for endodontic use. ${ }^{19,20}$ However, the use of CBCT is recent, and due to its high cost, it is not widely used in epidemiological studies. This examination will potentially become routine in dental clinics due to its high quality, specificity, and the capability to produce 3D images. ${ }^{21}$

The present study showed that among the expected total of 44,736 teeth to be evaluated, 6,808 (15.2\%) teeth were absent, particularly molars $(28.3 \%)$ and premolars $(11.3 \%)$. Regarding the presence of periapical change, premolars and molars were predominant, with molars representing $74.3 \%$ and premolars $55.0 \%$ in the upper teeth and molars representing $61.7 \%$ and premolars $40.1 \%$ in the lower teeth. These findings may be related to the fact that premolars and molars have higher anatomical variability and types of root branching. ${ }^{22}$ Root canal morphology of these teeth is complex and variable, making endodontic treatment more difficult and consequently reducing prognostic predictability. ${ }^{20}$ These variations represent a source of infection and a major cause of treatment failure, even leading to early loss of dental elements. ${ }^{23}$

The data revealed a predominance of females $(n=856$, $61.2 \%$ ) over males $(n=542,38.8 \%)$. This finding can be explained by women's greater concern for and awareness of self-care. ${ }^{24,25}$ Overall, there was no statistically significant gender difference in the present study.

Odesjö et $\mathrm{al}^{26}$ reported that of 17,430 teeth examined, $1,492(8.6 \%)$ underwent endodontic treatment. De Moor et $\mathrm{al}^{8}$ reported $6.8 \%$ of 4,217 examined teeth. Kirkevang et $\mathrm{al}^{27}$ found $773(4.8 \%)$ of a total of 15,284 . Chen et $\mathrm{al}^{28}$ found $4.8 \%$ of examined teeth, and Matijevic ${ }^{9}$ reported an endodontic treatment prevalence of $8.5 \%$. These results corroborate the present study, where the occurrence of endodontic treatment was $6.1 \%$. However, results slightly below this average were reported for teeth with endodontic treatment. ${ }^{29-31}$ Several studies, including Boucher et $\mathrm{al}^{32}$ and Tsuneishi et $\mathrm{al}^{33}$ had found that 23 and $21 \%$ of teeth had endodontic treatment respectively, and Hollanda et al, ${ }^{34}$ who reported a $21.4 \%$ prevalence of endodontically treated teeth in an adult Brazilian population, have reported higher occurrences. The discrepancies observed among the results of different studies may be explained based on the different populations and study concepts.

In the present study, of the 2,329 teeth with endodontic treatment, premolar teeth were treated most frequently ( $8.24 \%)$, followed by molars (6.51\%) and incisors (5.01\%). Canines had the lowest frequency of endodontic treatment (3.64\%). However, when comparing upper and lower teeth, the lower incisors and lower canines had the lowest prevalence rates of endodontic treatment (1.1 and $1.3 \%$ respectively) and the upper premolars and upper 
incisors had the highest prevalence rates (8.8 and $8.3 \%$ respectively). Corroborating this study, Jiménez-Pinzón et $\mathrm{al}^{35}$ estimated the prevalence rates of AP and endodontic treatment in an adult Spanish population. Premolars and molars had higher incidences of endodontic treatment, 2.8 and $2.7 \%$ respectively. However, Kirkevang et $\mathrm{al}^{27}$ investigated the prevalence rates of endodontically treated teeth and AP in a Danish population and found that molars were treated significantly more often (8.1\%) compared with premolars $(5.4 \%)$ and anterior teeth $(2.5 \%)$.

Matijevic et $\mathrm{al}^{9}$ observed that in the maxilla, the teeth often treated endodontically were the second premolars, while in the mandible, the most commonly treated were the first molars. In the present study, it can be confirmed that the upper premolars had the greatest frequency of endodontic treatment, followed by the upper incisors and lower molars. The posterior teeth had a higher incidence of endodontic treatment. This finding may be related to the fact that these teeth do not represent the esthetic portion of the dental elements and are therefore, not cared properly. The lack of proper care suggests that the posterior teeth suffer greater effects of microorganisms in the oral environment, leading to coronal destruction (caries) and subsequent endodontic treatment.

The presence of periapical radiolucency has been used as a criterion to determine failure of endodontic treatment. ${ }^{35}$ Although radiography provides a static picture of a dynamic process at the time of radiographic evaluation, AP of endodontically treated teeth may appear either during the development or treatment process. ${ }^{36}$ Therefore, sectional investigations can provide reliable information on the prevalence of AP in a given population. ${ }^{37}$ In the present study, it was observed that AP was present in $52.4 \%$ of endodontically treated teeth. A total of $60.3 \%$ of obturations were considered to be of inadequate quality, and $52.4 \%$ of the apical limits of obturation were considered inadequate. The relationship between the quality of endodontic treatment (quality of obturation and apical limit) and its association with AP has been demonstrated in other epidemiological studies. ${ }^{16,30,32,34,38,39}$

Apical periodontitis is a sequel of endodontic infection and manifests as the host defense response to microbial challenge emanating from the root canal system. ${ }^{12}$ Most failures occur when treatment procedures, primarily of a technical nature, do not reach satisfactory levels regarding the control and elimination of infection. ${ }^{40}$ The apical anatomy consists of the largest foraminal opening and smallest constriction diameter, located on average $0.5 \mathrm{~mm}$ from the root apex, and is extremely important to the apical limit of the obturation. ${ }^{41}$ The results of the present study reveal a correlation between the presence of periapical change and obturation quality. When obturation quality was considered inadequate, periapical changes were present in $45 \%$ of cases. When deemed adequate, they were present in only $7 \%$ of cases. Correlating the presence of periapical change and the apical limit of the obturation, when this last one was considered adequate, apical changes were present in $10 \%$ of cases, and when inadequate, in $42 \%$. Periapical changes were present in $52 \%$ of cases, regardless of quality and the apical limit of the obturation.

The quality of both endodontic treatment and coronal restoration affects treatment success. ${ }^{10,42,43}$ Bacterial elements can penetrate through the obturation, from the coronal portion to the apical tip after a period of exposure to artificial saliva or bacterial culture. ${ }^{44,45}$ Coronal sealing between sessions and final restoration represents a critical moment during which all the care taken during the clinical procedure can be jeopardized. ${ }^{46}$ Furthermore, definitive restoration following the completion of endodontic treatment is of vital importance for endodontic success. ${ }^{47,48}$

Data collection has revealed that concerning age, an increased presence of periapical changes was observed with aging. Inadequate obturation quality percentage also increased with age. The prevalence of AP increased with age, and the disease appears to be associated mainly with previously endodontically treated teeth. ${ }^{49}$ The difference in periapical status is most related to age and root canal obturation quality. ${ }^{18}$

Root canal treatment quality is shaped by the knowledge, attitude, and skills of the dentist; changes of opinion and clinical performance in the context of dental practice must be justified. ${ }^{50}$ The obvious interrelationship between the factors analyzed in the present study demonstrates an old concern that remains today, despite technological advances in materials, equipment, automated preparation techniques, apical locators, surgical microscopes, CBCT for diagnosis, and dissemination of knowledge in an accessible way. The results indicate that there is a long way to go before the desired success in endodontic treatment is achieved.

\section{CONCLUSION}

Based on the methodology used, it can be concluded that AP is associated with the quality of both endodontic treatment and coronal restoration and significantly affects the success rate of endodontic treatment.

\section{REFERENCES}

1. Sipavičiūtè E, Manelienè R. Pain and flare-up after endodontic treatment procedures. Stomatologija 2014;16(1):25-30.

2. George R. Nonsurgical retreatment $v$ s endodontic microsurgery: assessing success. Evid Based Dent 2015 Sep;16(3): 82-83. 
3. Kim SY, Kim SH, Cho SB, Lee GO, Yang SE. Different treatment protocols for different pulpal and periapical diagnoses of 72 cracked teeth. J Endod 2013 Apr;39(4):449-452.

4. Kamberi B, Hoxha V, Stavileci M, Dragusha E, Kuçi A, Kqiku L. Prevalence of apical periodontitis and endodontic treatment in a Kosovar adult population. BMC Oral Health 2011 Nov;29(11):32.

5. Anderson AC, Hellwig E, Vespermann R, Wittmer A, Schmid M, Karygianni L, Al-Ahmad A. Comprehensive analysis of secondary dental root canal infections: a combination of culture and culture-independent approaches reveals new insights. PLoS One 2012;7(11):e49576.

6. Siqueira JF Jr, Rôças IN, Alves FR, Campos LC. Periradicular status related to the quality of coronal restorations and root canal fillings in a Brazilian population. Oral Surg Oral Med Oral Pathol Oral Radiol Endod 2005 Sep;100(3):369-374.

7. Interliche R, Marchesan MA, Silva SR, Pécora JD, SilvaSousa YT, Sousa-Neto MD. Influence of Hero apical instruments on cleaning ovoid-shaped root canals. Braz Oral Res 2011 Jul-Aug;25(4):314-318.

8. De Moor RJ, Hommez GM, De Boever JG, Delmé KI, Martens GE. Periapical health related to the quality of root canal treatment in a Belgian population. Int Endod J 2000 Mar;33(2):113-120.

9. Matijevic J, Cizmeković Dadić T, Prpic Mehicic G, Ani I, Slaj M, Jukić Krmek S. Prevalence of apical periodontitis and quality of root canal filings in population of Zagreb, Croatia: a crosssectional study. Croat Med J 2011 Dec;52(6):679-687.

10. Gündüz K, Avsever H, Orhan K, Demirkaya K. Cross-sectional evaluation of the periapical status as related to quality of root canal fillings and coronal restorations in a rural adult male population of Turkey. BMC Oral Health 2011 Jun;20(11):20.

11. Reyhani MF, Ghasemi N, Rahimi S, Milani AS, Barhaghi MH, Azadi A. Apical microleakage of AH Plus and MTA Fillapex ${ }^{\circledR}$ sealers in association with immediate and delayed post space preparation: a bacterial leakage study. Minerva Stomatol 2015 Jun;64(3):129-134.

12. van der Waal SV, Lappin DF, Crielaard W. Does apical periodontitis have systemic consequences? The need for wellplanned and carefully conducted clinical studies. Br Dent J 2015 May;218(9):513-516.

13. Segura-Egea JJ, Jiménez-Pinzón A, Poyato-Ferrera M, VelascoOrtega E, Ríos-Santos JV. Periapical status and quality of root fillings and coronal restorations in an adult Spanish population. Int Endod J 2004 Aug;37(8):525-530.

14. Preethee T, Kandaswamy D, Hannah R. Molecular identification of an Enterococcus faecalis endocarditis antigen efaA in root canals of therapy-resistant endodontic infections. J Conserv Dent 2012 Oct;15(4):319-322.

15. Shahravan A, Haghdoost AA. Endodontic epidemiology. Iran Endod J 2014 Spring;9(2):98-108.

16. Bueno MR, Estrela C. Prevalence of endodontic treatment and apical periodontitis in several populations of world, detected by panoramic and periapical radiography and cone beam computed tomography. Robrac 2008;17(43):79-90.

17. Orstavik D, Kerekes K, Eriksen HM. The periapical index: a scoring system for radiographic assessment of apical periodontitis. Endod Dent Traumatol 1986 Feb;2(1):20-34.

18. Persić R, Kqiku L, Brumini G, Husetić M, Pezelj-Ribarić S, Brekalo Prso I, Städtler P. Difference in the periapical status of endodontically treated teeth between the samples of Croatian and Austrian adult patients. Croat Med J 2011 Dec;52(6):672-678.
19. Durack C, Patel S. Cone beam computed tomography in endodontics. Braz Dent J 2012;23(3):179-191.

20. Han X, Yang H, Li G, Yang L, Tian C, Wang Y. A study of the distobuccal root canal orifice of the maxillary second molars in Chinese individuals evaluated by cone-beam computed tomography. J Appl Oral Sci 2012 Sep-Oct;20(5):563-567.

21. Geist JR. Cone-beam computed tomography: strengths, weaknesses, and controversies. J Mich Dent Assoc 2011 Mar;93(3):48-62.

22. Bürklein S, Grund C, Schäfer E. Relationship between root apices and the mandibular canal: a cone-beam computed tomographic analysis in a German population. J Endod 2015 Oct;41(10):1696-1700.

23. Mărgărit R, Andrei OC. Anatomical variations of mandibular first molar and their implications in endodontic treatment. Rom J Morphol Embryol 2011;52(4):1389-1392.

24. Lupi-Pegurier L, Bertrand MF, Muller-Bolla M, Rocca JP, Bolla M. Periapical status, prevalence and quality of endodontic treatment in an adult French population. Int Endod J 2002 Aug;35(8):690-697.

25. Sunay H, Tanalp J, Dikbas I, Bayirli G. Cross-sectional evaluation of the periapical status and quality of root canal treatment in a selected population of urban Turkish adults. Int Endod J 2007 Feb;40(2):139-145.

26. Odesjö B, Helldén L, Salonen L, Langeland K. Prevalence of previous endodontic treatment, technical standard and occurrence of periapical lesions in a randomly selected adult, general population. Endod Dent Traumatol 1990 Dec;6(6): 265-272.

27. Kirkevang LL, Hörsted-Bindslev P, Ørstavik D, Wenzel A. Frequency and distribution of endodontically treated teeth and apical periodontitis in an urban Danish population. Int Endod J 2001 Apr;34(3):198-205.

28. Chen CY, Hasselgren G, Serman N, Elkind MS, Desvarieux M, Engebretson SP. Prevalence and quality of endodontic treatment in the Northern Manhattan elderly. J Endod 2007 Mar;33(3):230-234.

29. Gomes AC, Nejaim Y, Silva AI, Haiter-Neto F, Cohenca N, Zaia AA, Silva EJ. Influence of endodontic treatment and coronal restoration on status of periapical tissues: a conebeam computed tomographic study. J Endod 2015 Oct;41(10): 1614-1618.

30. Gulsahi K, Gulsahi A, Ungor M, Genc Y. Frequency of rootfilled teeth and prevalence of apical periodontitis in an adult Turkish population. Int Endod J 2008 Jan;41(1):78-85.

31. Touré B, Kane AW, Sarr M, Ngom CT, Boucher Y. Prevalence and technical quality of root fillings in Dakar, Senegal. Int Endod J 2008 Jan;41(1):41-49.

32. Boucher Y, Matossian L, Rilliard F, Machtou P. Radiographic evaluation of the prevalence and technical quality of root canal treatment in a French subpopulation. Int Endod J 2002 Mar;35(3):229-238.

33. Tsuneishi M, Yamamoto T, Yamanaka R, Tamaki N, Sakamoto T, Tsuji K, Watanabe T. Radiographic evaluation of periapical status and prevalence of endodontic treatment in an adult Japanese population. Oral Surg Oral Med Oral Pathol Oral Radiol Endod 2005 Nov;100(5):631-635.

34. Hollanda AC, de Alencar AH, Estrela CR, Bueno MR, Estrela C. Prevalence of endodontically treated teeth in a Brazilian adult population. Braz Dent J 2008;19(4):313-317.

35. Jiménez-Pinzón A, Segura-Egea JJ, Poyato-Ferrera M, VelascoOrtega E, Ríos-Santos JV. Prevalence of apical periodontitis 
and frequency of root-filled teeth in an adult Spanish population. Int Endod J 2004 Mar;37(3):167-173.

36. Morgental RD, Santos RB, Rösing CK, Chanin Tdo A, Figueiredo JA. Interference of partial visual analysis of root filling quality and apical status on retreatment decisions. J Appl Oral Sci 2012 Mar-Apr;20(2):206-211.

37. Terças AG, de Oliveira AE, Lopes FF, Maia Filho EM. Radiographic study of the prevalence of apical periodontitis and endodontic treatment in the adult population of São Luis, MA, Brazil. J Appl Oral Sci 2006 Jun;14(3):183-187.

38. Georgopoulou MK, Spanaki-Voreadi AP, Pantazis N, Kontakiotis EG, Morfis AS. Periapical status and quality of root canal fillings and coronal restorations in a Greek population. Quintessence Int 2008 Feb;39(2):e85-92.

39. Shantiaee Y, Maziar F, Dianat O, Mahjour F. Comparing microleakage in root canals obturated with nanosilver coated guttapercha to standard gutta-percha by two different methods. Iran Endod J 2011 Fall;6(4):140-145.

40. Nair PN. Pathogenesis of apical periodontitis and the causes of endodontic failures. Crit Rev Oral Biol Med 2004 Nov;15(6):348-381.

41. Abarca J, Zaror C, Monardes H, Hermosilla V, Muñoz C, Cantin M. Morphology of the physiological apical foramen in maxillary and mandibular first molars. Int J Morphol 2014 Jun;32(2):671-677.

42. Valera MC, Maekawa LE, Chung A, Cardoso FG, Oliveira LD, Oliveira CL, Carvalho CA. The effect of sodium hypochlorite and ginger extract on microorganisms and endotoxins in endodontic treatment of infected root canals. Gen Dent 2014 May-Jun;62(3):25-29.
43. Tolias D,Koletsi K,Mamai-HomataE,Margaritis V,KontakiotisE. Apical periodontitis in association with the quality of root fillings and coronal restorations: a 14-year investigation in young Greek adults. Oral Health Prev Dent 2012;10(3):297-303.

44. Samiei M, Aghazade M, Farhadi F, Shahveghar N, Torab A, Vahid Pakdel SM. Sealing efficacy of single-cone obturation technique with MTA and CEM Cement: an in vitro bacterial leakage study. J Dent Res Dent Clin Dent Prospects 2014 Spring;8(2):77-83.

45. Haapasalo M, Udnæs T, Endal U. Persistent, recurrent, and acquired infection of the root canal system post-treatment. Endod Top 2003;6(1):29-56.

46. Srikumar GP, Varma KR, Shetty KH, Kumar P. Coronal microleakage with five different temporary restorative materials following walking bleach technique: an ex-vivo study. Contemp Clin Dent 2012 Oct;3(4):421-426.

47. De Castro PH, Pereira JV, Sponchiado EC Jr, Marques AA, Garcia Lda F. Evaluation of marginal leakage of different temporary restorative materials in endodontics. Contemp Clin Dent 2013 Oct;4(4):472-475.

48. Kitagawa R, Kitagawa H, Izutani N, Hirose N, Hayashi M, Imazato $\mathrm{S}$. Development of an antibacterial root canal filling system containing MDPB. J Dent Res 2014 Dec;93(12): 1277-1282.

49. Segura-Egea JJ, Martín-González J, Castellanos-Cosano L. Endodontic medicine: connections between apical periodontitis and systemic diseases. Int Endod J 2015 Oct;48(10):933-951.

50. Demant S, Markvart M, Bjørndal L. Quality-shaping factors and endodontic treatment amongst general dental practitioners with a focus on Denmark. Int J Dent 2012;2012:526137. 